\title{
Genetic determinants of plasma HDL-cholesterol levels in familial hypercholesterolemia
}

\author{
Emily S van Aalst-Cohen ${ }^{1}$, Angelique CM Jansen ${ }^{1}$, S Matthijs Boekholdt ${ }^{2}$, \\ Michael WT Tanck ${ }^{3}$, Marcel R Fontecha ${ }^{4}$, Suzanne Cheng ${ }^{4}$, Jia Li ${ }^{4}$, Joep C Defesche ${ }^{1}$, \\ Jan Albert Kuivenhoven ${ }^{1}$ and John JP Kastelein*,1
}

\author{
${ }^{1}$ Department of Vascular Medicine, Academic Medical Center, Amsterdam, The Netherlands; ${ }^{2}$ Department of \\ Cardiology, Academic Medical Center, Amsterdam, The Netherlands; ${ }^{3}$ Department of Clinical Epidemiology and \\ Biostatistics, Academic Medical Center, Amsterdam, The Netherlands; ${ }^{4}$ Department of Human Genetics, Roche \\ Molecular Systems, Inc., Alameda, CA, USA
}

The objective of this study was to determine the extent to which common genetic variants can explain the variation of high-density lipoprotein cholesterol (HDL-C) plasma levels in familial hypercholesterolemia (FH). FH is characterized by elevated low-density lipoprotein cholesterol levels and premature cardiovascular disease (CVD). Although low HDL-C levels have been shown to affect the severity of the clinical phenotype, little is known about the factors that determine HDL-C levels in these patients. A cohort of 1002 heterozygous FH patients was genotyped for polymorphisms in the genes encoding for ATPbinding cassette transporter A1, apolipoprotein (apo) AIV, apoCIII, apoE, cholesteryl transfer ester protein, hepatic lipase, lipoprotein lipase, and two paraoxonases. Multiple linear regression showed that, together, these polymorphisms explain only 3.9\% of the variation of HDL-C plasma levels. When significant two-way interactions between the polymorphisms were also taken into account, the explained variation rose to $12.5 \%$. In a regression model that also incorporated sex, smoking, alcohol use, body mass index, and concomitant beta-blocker use as covariates, the explained variation of HDL-C plasma levels even increased to $32.5 \%$. This study provides direct evidence that multiple, modestly penetrant, but highly prevalent, polymorphisms can explain a substantial part of the variation of HDL-C plasma levels in a representative large cohort of heterozygous FH patients.

European Journal of Human Genetics (2005) 13, 1137-1142. doi:10.1038/sj.ejhg.5201467;

published online 20 July 2005

Keywords: hypercholesterolemia; high-density lipoprotein cholesterol; genetics

Introduction

Familial hypercholesterolemia (FH) is a common, hereditary disorder, characterized by elevated levels of plasma low-density lipoprotein cholesterol (LDL-C) and premature cardiovascular disease (CVD). FH is caused by mutations in

*Correspondence: Professor JJP Kastelein, Department of Vascular Medicine, Academic Medical Center, Room F4-159.2, Meibergdreef 9, 1105 AZ Amsterdam, The Netherlands. Tel: +31 20566 6612;

Fax: + 3120566 9343; E-mail: e.vandongen@amc.uva.nl

Received 29 March 2005; revised 8 June 2005; accepted 9 June 2005; published online 20 July 2005 the low-density-lipoprotein receptor $(L D L-R)$ gene, leading to an insufficient uptake of LDL-C from the circulation. ${ }^{1}$ Characteristically, the mean age of onset of CVD is between 40 and 45 years in male $\mathrm{FH}$ patients and 10 years later in female FH patients., ${ }^{1,2}$ Although the cause of $\mathrm{FH}$ is monogenic, there is wide variation in the onset and severity of atherosclerotic disease in these patients. ${ }^{3}$ This is often suggested to be related to environmental and additional genetic risk factors. In this respect, low highdensity-lipoprotein cholesterol (HDL-C) has been shown to be an independent risk factor for the development of CVD in $\mathrm{FH}$ patients. ${ }^{4-8}$ Therefore, early identification of $\mathrm{FH}$ 
patients with low HDL-C, in addition to the development of therapeutic strategies to specifically raise HDL-C, may be warranted. ${ }^{9}$ HDL-C levels, however, are affected by sex, obesity, smoking, diet, alcohol consumption, exercise, and medication use, in addition to numerous genetic factors, ${ }^{10,11}$ but the relative contribution of these factors to HDL-C levels in FH patients is not known. ${ }^{12}$ It is assumed that the combined effects of multiple common genetic variants might explain a large part of HDL-C variation. ${ }^{13}$ We therefore determined the contribution of polymorphisms in a number of HDL-C-related gene loci to the variation of HDL-C plasma levels in $\mathrm{FH}$.

\section{Methods}

\section{Study design and study population}

The present investigation was a retrospective, multicenter, cohort study. The study design and study population have been described elsewhere. ${ }^{8}$ Briefly, lipid clinics in the Netherlands submit DNA samples from clinically suspected FH patients to a central laboratory for LDL-receptor mutation analysis. ${ }^{14}$ We randomly selected hypercholesterolemic patients from this DNA-bank database with the aid of a computer program (Microsoft Excel). These patients had been referred from 27 lipid clinics throughout the Netherlands. A total of $2400 \mathrm{FH}$ patients were included in this study. The FH diagnostic criteria were based on internationally established criteria. ${ }^{15-17}$

Phenotypic data (including detailed information on factors known to influence plasma HDL-C levels) were acquired by reviewing patient's medical records by a trained team of data collectors. ${ }^{18}$ Guidelines for data collection from medical records were constructed for the purpose of the study and have been published. ${ }^{18}$ Written informed consent was obtained from all living patients. The Ethics Institutional Review Board of each participating hospital approved the protocol.

\section{Factors known to influence plasma HDL-C levels}

Smoking was defined as ever having smoked (yes/no). Body mass index (BMI) was calculated from height and length $\left(\mathrm{kg} / \mathrm{m}^{2}\right)$. Alcohol use was determined at the time of the first visit to the lipid clinic (yes/no). Hypertension was defined when the diagnosis had been made and when antihypertensive medication was prescribed, or if three consecutive measurements of blood pressure were $>140 \mathrm{mmHg}$ systolic or $>90 \mathrm{mmHg}$ diastolic. Concomitant beta-blocker and/or diuretic use were assessed at the time of determination of plasma HDL-C concentration (yes/no). Diabetes mellitus was defined when the diagnosis had been made and medication (insulin or oral antidiabetics) was prescribed, or by a fasting plasma glucose of $>6.9 \mathrm{mmol} / \mathrm{l}$.

\section{Laboratory analysis}

All laboratory parameters were measured in fasting blood samples after at least 6 weeks of withdrawal of any lipid- lowering medication. The presented values are those from as close to the first lipid clinic visit as possible, with a maximum time-span of two years. Plasma total cholesterol, HDL-C, and triglycerides (TG) were measured by standard enzymatic methods. LDL-C concentrations were calculated by means of the Friedewald formula. ${ }^{19}$ Mutations in the $L D L-R$ gene were assessed as described previously. ${ }^{20}$

\section{Selection of polymorphisms}

Using the current literature, we selected 25 DNA polymorphisms in nine genes that are known to affect HDL-C levels or that could potentially affect HDL-C levels. We selected the following 23 biallelic polymorphisms in eight HDL-C-related genes for the present analysis: $A B C A 1_{\text {C69T, }}, A B C A 1_{\text {ins } 319}, A B C A 1_{\text {Arg219Lys, }}$ ApoAIV $V_{\text {Thr347Ser }}$ ApoAIV Gln360His, $\quad$ ApoCIII $_{C(-641) A}, \quad$ ApoCIII $_{C(-482) T}$, ApoCIII $_{\text {Thr }(-455) C y s,}$ ApoCIII ${ }_{\text {C110oT, }}$ ApoCIII ${ }_{\text {C3175G }}$, ApoCIII $_{\text {T3206G }}, \quad$ CETP $_{C(-629) A}, \quad$ CETP $_{\text {Taq1B }}, \quad$ CETP $_{C(-631) A}$, CETP $_{\text {Ile405Val }}, H L_{C(-514) T}, L P L_{T(-93) G}, L P L_{A s p 9 A s n}, L P L_{\text {Asn291Ser }}$ $L P L_{\text {Ser447Stop, }} \quad P O N 1_{\text {Leu55Met }}, \quad P O N 1_{\text {Gln192Arg, }}$ and PON2 $2_{\text {Ser } 311 C y s}$, and we included the triallelic ApoE polymorphism, determined by arginine/cysteine variations at codons 112 and 158, in our analyses.

\section{Genetic analyses}

Genomic DNA was extracted from peripheral blood leukocytes according to a standard protocol. Genotyping was performed by Roche Molecular Systems, CA, USA. For all biallelic sites, genotypes were generated using a PCR and immobilized probe assay, as described previously by Cheng et $a .^{21}$ Laboratory personnel had no access to either identifiable or clinical information.

\section{Statistical analysis}

All polymorphism genotypes were treated as categorical variables. The effect of individual polymorphism genotypes on HDL-C concentration was estimated by linear regression, without adjustment for covariates. Subsequently, four different backward (multiple) linear regression models were used to examine the independent effects of the polymorphisms on HDL-C concentration. The first (main effects) model included only the main effects of the 25 polymorphisms. The second (combined effects) model included the main effects and a selection of two-way interactions (gene-gene, gene-environment, and environment-environment interactions). All two-way interaction terms were assessed, and those that were significant after adjustment for the main effects of all polymorphisms were included. Backward selection was then performed on the main effects of the polymorphisms not included in the selected interactions. The remaining two models consisted of the above-mentioned models with adjustment for a set of five covariates, that is: sex, smoking, alcohol use, BMI, and concomitant beta-blocker use. A $P$-value of $<0.05$ was considered significant. For all four models, the percentage 
explained $\left(R^{2}\right)$ variation in baseline HDL-C concentration was calculated. Statistical analyses were performed using SPSS software (version 11.0, Chicago, IL, USA).

\section{Results}

From the 2400 patients who comprised the study population, a total of 1002 individuals could be completely genotyped for 25 selected polymorphisms in addition to having complete clinical data. These 1002 subjects did not differ significantly from the original cohort of 2400 patients with regard to any of the clinical characteristics. The characteristics of the study population are summarized in Table 1 . The average HDL-C concentration without lipid-lowering medication was $1.20 \pm 0.35 \mathrm{mmol} / \mathrm{l}$. Among patients, beta-blocker use was more prevalent than diuretic use (11 vs 4\%). Furthermore, beta-blocker use had a significant $(P<0.0001)$ effect on HDL levels, whereas diuretic use did not influence HDL levels $(P=0.99)$. Therefore, beta-blocker use alone was chosen as a covariate in the statistical models (see below). The presence of diabetes mellitus did not contribute to plasma HDL levels in this population. Therefore, diabetes mellitus was not included as a covariate in the statistical models (see below).

A total of 193 patients (19\%) had experienced a cardiovascular event before plasma HDL determination.

Table 1 Clinical characteristics of the genotyped $\mathrm{FH}$ patients

\begin{tabular}{|c|c|}
\hline Number of subjects & 1002 \\
\hline $\begin{array}{l}\text { Demographics } \\
\text { Male sex (\%) } \\
\text { Age at first visit to lipid clinic } \\
\text { Cardiovascular event prior to first clinic } \\
\text { visit }(\%)\end{array}$ & $\begin{array}{c}49.0 \\
44.1 \pm 12.3 \\
\frac{19}{19}\end{array}$ \\
\hline $\begin{array}{l}\text { Risk factors } \\
\text { Smoking, ever (\%) } \\
\text { Alcohol use at first visit to lipid clinic (\%) } \\
\text { Hypertension (\%) } \\
\text { Diabetes mellitus (\%) }\end{array}$ & $\begin{array}{l}73.9 \\
75.7 \\
9.4 \\
4.8\end{array}$ \\
\hline $\begin{array}{l}\text { Physical examination } \\
\text { BMl }\left(\mathrm{kg} / \mathrm{m}^{2}\right) \\
\text { Systolic blood pressure }(\mathrm{mmHg}) \\
\text { Diastolic blood pressure }(\mathrm{mmHg}) \\
\text { Tendon xanthomas }(\%)\end{array}$ & $\begin{array}{c}25.1 \pm 3.5 \\
134 \pm 18 \\
82 \pm 10 \\
44 \%\end{array}$ \\
\hline $\begin{array}{l}\text { Laboratory parameters } \\
\text { Total cholesterol }(\mathrm{mmol} / \mathrm{l}) \\
\text { LDL cholesterol }(\mathrm{mmol} / \mathrm{l}) \\
\text { HDL cholesterol }(\mathrm{mmol} / \mathrm{l}) \\
\text { Triglycerides }(\mathrm{mmol} / \mathrm{l})\end{array}$ & $\begin{array}{c}9.36 \pm 1.94 \\
7.33 \pm 1.95 \\
1.20 \pm 0.35 \\
1.57(1.11-2.23)\end{array}$ \\
\hline
\end{tabular}

However, due to confounding with the other covariates in the model (sex, smoking, body mass index, alcohol use, and beta-blocker use), the presence of a prior CVD event (as a covariate) did not remain significant in the statistical model. These risk factors have been studied extensively in this study population, ${ }^{8}$ and are confirmed classical risk factors for the development of CVD in FH. Therefore, in a statistical model, the presence of CVD cannot function as a statistically independent predictor of plasma HDL.

Genotype counts and mean HDL-C plasma levels according to genotype are presented for the 23 biallelic SNPs in Table 2. All but two (ApoAIV $V_{\text {Thr347Ser }}$ and ApoC$I I I_{T 3206 G}$ ) of the 23 polymorphisms studied were in HardyWeinberg equilibrium (HWE). We also considered the triallelic ApoE polymorphism that is determined by arginine/cysteine variations at codons 112 and 158 . The $\mathrm{E} 3 \mathrm{E} 3, \mathrm{E} 3 \mathrm{E} 4, \mathrm{E} 2 \mathrm{E} 3, \mathrm{E} 2 \mathrm{E} 4, \mathrm{E} 4 \mathrm{E} 4$, and E2E2 genotypes were defined in $574,286,64,30,46$, and two subjects, respectively. The ApoE polymorphism was in HWE. HDLC plasma levels for these genotypes were $1.20( \pm 0.35), 1.20$ $( \pm 0.35), 1.21( \pm 0.37), 1.02( \pm 0.21), 1.24( \pm 0.37)$, and $1.12( \pm 0.09) \mathrm{mmol} / \mathrm{l}$, respectively.

\section{Effect of multiple polymorphisms and their interactions on HDL-C plasma levels}

After the backward selection procedure, the main-effects model consisted of five polymorphisms that together accounted for $3.9 \%$ of the population variability in HDL$\mathrm{C}$ plasma levels (Table 3 ). These five polymorphisms were CETP $_{\text {TaqIB }}, A B C A 1_{\text {Arg219Lys }}, L P L_{\text {Asn291Ser }}, A p o C I I I_{C 1100 T}$, and ApoAIV $V_{\text {Thr347Ser }}$.

The combined-effects model incorporated 12 main effects and five gene-gene interaction effects, and explained $12.5 \%$ of HDL-C variation. The interactions were $\left(A B C A 1_{C 69 T} \times A p o A I V_{\text {Thr347Ser }}\right),\left(A B C A 1_{C 69 T} \times A p o C I I I_{T 3206 G}\right)$, $\left(A p o C I I I_{C(-482) T} \times C E T P_{T a q I B}\right),\left(A p o C I I I_{T(-455) C} \times L P L_{S e r 4475 t o p}\right)$, and $\left(A p o E \times C E T P_{T a q I B}\right)$, with individual $R^{2}$-values of 1.0 , $1.9,1.8,2.0$, and $1.6 \%$, respectively. In addition to the main effects of the polymorphisms in the interaction terms, the main effects of $A B C A 1_{\text {Arg219Lys }}$, ApoCIII $I_{C 1100 T}$, $H L_{C(-514) T}$, and $L P L_{A s n 291 S e r}$ remained significant.

When the five covariates (sex, smoking, alcohol use, BMI, and concomitant beta-blocker use) were incorporated into the model, four polymorphisms ( $A B C A 1_{A r g 219 L y s}$, $H L_{C(-514) T}, L P L_{A s n 291 S e r}$, and $\left.C E T P_{T a q I B}\right)$ remained in the main-effects model, explaining $20.2 \%$ of HDL-C variation. The covariate-adjusted combined-effects model could even explain $32.5 \%$ of HDL-C variation, while containing 18 polymorphism main effects and eight gene-gene, two geneenvironment, and one environment-environment interactions. The most important gene-gene interactions were $\left(A B C A 1_{C 69 T} \times A\right.$ poCIII $\left.I_{T 3206 G}\right), \quad\left(\right.$ ApoCIII $\left._{C(-482) T} \times C_{\text {CETP }}{ }_{T a q 1 B}\right)$, $\left(L P L_{\text {Ser447Stop }} \times\right.$ PON2 $\left.2_{\text {Ser311Cys }}\right), \quad$ and $\left(P O N 2_{\text {Ser } 311 C y s} \times\right.$ $C_{\text {ETP }}$ Ile405Val $)$, with individual $R^{2}$-values of $2.1,1.8,1.1$, and $1.1 \%$, respectively. The most significant gene-environ- 
Table 2 Genotype counts and HDL-C plasma levels for all investigated SNPs

\begin{tabular}{|c|c|c|c|c|c|c|c|c|c|}
\hline \multirow[b]{2}{*}{ Gene } & \multirow[b]{2}{*}{ SNP } & \multicolumn{2}{|c|}{ Common allele homozygotes } & \multicolumn{2}{|c|}{ Heterozygotes } & \multicolumn{2}{|c|}{ Rare allele homozygotes } & \multirow[b]{2}{*}{ P-value } & \multirow[b]{2}{*}{$R^{2}(\%)$} \\
\hline & & Mean $\pm S D$ & $n$ & $M e a n \pm S D$ & $n$ & Mean $\pm S D$ & $n$ & & \\
\hline$A B C A 1$ & C69T & $1.20 \pm 0.37$ & 451 & $1.20 \pm 0.33$ & 429 & $1.20 \pm 0.33$ & 122 & 0.981 & 0.01 \\
\hline$A B C A 1$ & ins319 & $1.21 \pm 0.34$ & 778 & $1.17 \pm 0.35$ & 210 & $1.17 \pm 0.36$ & 14 & 0.337 & 0.2 \\
\hline$A B C A 1$ & Arg219Lys & $1.18 \pm 0.32$ & 544 & $1.24 \pm 0.38$ & 391 & $1.15 \pm 0.29$ & 67 & 0.011 & 0.9 \\
\hline АроA4 & Thr347Ser & $1.21 \pm 0.35$ & 679 & $1.18 \pm 0.35$ & 271 & $1.11 \pm 0.32$ & 52 & 0.073 & 0.5 \\
\hline ApoA4 & $\mathrm{Gln} 360 \mathrm{His}$ & $1.20+0.35$ & 847 & $1.19+0.32$ & 152 & $1.00+0.43$ & 3 & 0.569 & 0.1 \\
\hline АроС 3 & $C(-641) A$ & $1.21 \pm 0.33$ & 373 & $1.20 \pm 0.36$ & 468 & $1.17 \pm 0.34$ & 161 & 0.455 & 0.2 \\
\hline АpoC3 & $C(-482) T$ & $1.20 \pm 0.33$ & 524 & $1.20 \pm 0.36$ & 395 & $1.17 \pm 0.36$ & 83 & 0.749 & 0.1 \\
\hline АроC 3 & $\mathrm{~T}(-455) \mathrm{C}$ & $1.20 \pm 0.33$ & 388 & $1.21 \pm 0.36$ & 460 & $1.17 \pm 0.35$ & 154 & 0.575 & 0.1 \\
\hline АроС 3 & C1100T & $1.22 \pm 0.35$ & 535 & $1.18 \pm 0.36$ & 378 & $1.17 \pm 0.32$ & 89 & 0.165 & 0.4 \\
\hline Apo 3 & T3206G & $1.19+0.32$ & 396 & $1.21+0.37$ & 428 & $1.18+0.34$ & 178 & 0.507 & 0.1 \\
\hline ApoC3 & C3175G & $1.20 \pm 0.34$ & 782 & $1.18 \pm 0.36$ & 206 & $1.15 \pm 0.23$ & 14 & 0.640 & 0.1 \\
\hline CETP & $C(-629) A$ & $1.16 \pm 0.32$ & 262 & $1.20 \pm 0.34$ & 513 & $1.25 \pm 0.39$ & 227 & 0.010 & 0.9 \\
\hline CETP & $C(-631) A$ & $1.20 \pm 0.35$ & 865 & $1.17 \pm 0.34$ & 131 & $1.35 \pm 0.40$ & 6 & 0.413 & 0.2 \\
\hline CETP & Ile405Val & $1.20 \pm 0.35$ & 454 & $1.20 \pm 0.35$ & 436 & $1.19 \pm 0.33$ & 112 & 0.931 & 0.01 \\
\hline CETP & Taq1B & $1.15+0.32$ & 320 & $1.21+0.34$ & 504 & $1.26+0.41$ & 178 & 0.005 & 1.1 \\
\hline$H L$ & $C(-514) T$ & $1.18 \pm 0.34$ & 602 & $1.23 \pm 0.36$ & 339 & $1.23 \pm 0.34$ & 61 & 0.094 & 0.5 \\
\hline$L P L$ & $T(-93) G$ & $1.20 \pm 0.35$ & 959 & $1.09 \pm 0.26$ & 42 & 1.21 & 1 & 0.109 & 0.4 \\
\hline$L P L$ & Asp9Asn & $1.20 \pm 0.35$ & 965 & $1.10 \pm 0.26$ & 36 & 1.21 & 1 & 0.208 & 0.3 \\
\hline$L P L$ & Asn291Ser & $1.20 \pm 0.35$ & 934 & $1.08 \pm 0.29$ & 67 & 0.96 & 1 & 0.011 & 0.9 \\
\hline$L P L$ & Ser447X & $1.20+0.35$ & 828 & $1.23+0.33$ & 160 & $1.17+0.32$ & 14 & 0.554 & 0.1 \\
\hline $\mathrm{PON}_{1}$ & Met55Leu & $1.20 \pm 0.35$ & 427 & $1.19 \pm 0.34$ & 449 & $1.19 \pm 0.32$ & 126 & 0.762 & 0.1 \\
\hline $\mathrm{PON}_{1}$ & Gln192Arg & $1.20 \pm 0.34$ & 470 & $1.20 \pm 0.35$ & 432 & $1.18 \pm 0.33$ & 100 & 0.820 & 0.01 \\
\hline $\mathrm{PON}_{2}$ & Ser311Cys & $1.19 \pm 0.35$ & 590 & $1.22 \pm 0.34$ & 348 & $1.17 \pm 0.36$ & 64 & 0.432 & 0.2 \\
\hline
\end{tabular}

$\mathrm{HDL}-\mathrm{C}$ levels are presented as mean (in $\mathrm{mmol} / \mathrm{l}) \pm \mathrm{SD}$ (conversion factor for $\mathrm{mmol} / \mathrm{l}$ to $\mathrm{mg} / \mathrm{dl}$ : multiply by 0.002586 ). ABCA1 indicates ATP-binding cassette A1; ApoA4 = apolipoprotein A4; ApoC3 = apolipoprotein C3; CETP= cholesteryl ester transfer protein; $\mathrm{HL}=$ hepatic lipase; $\mathrm{LPL}=$ lipoprotein lipase; $\mathrm{PON}=$ paraoxonase.

Table 3 Explained variation of HDL-C plasma concentration

\begin{tabular}{lcc}
\hline Variables & $\begin{array}{c}\text { Main effects model } \\
\text { (main effects only) }\end{array}$ & $\begin{array}{c}\text { Combined effects model } \\
\text { (main effects+selected } \\
\text { two-way interactions) }\end{array}$ \\
\hline $\begin{array}{l}\text { Genotypes } \\
\text { Genotypes plus } \\
\text { covariates }\end{array}$ & $20.2 \%(10)$ & $12.5 \%(42)$ \\
\hline
\end{tabular}

$R^{2}$-values for multiple linear regression models incorporating all genetic variants only, and genetic variants plus covariates (sex, smoking, alcohol, BMI, and concomitant beta-blocker use). Values are presented for models that incorporate main effects only, and main effects plus two-way interactions that contributed significantly to the explained HDL-C variation. The number of variables per model is given between parentheses.

ment interactions were $\left(C{ } T P_{\text {Ile } 405 \mathrm{Val}} \times\right.$ alcohol use $)$ and $\left(P O N_{1 \text { Leu } 55 \text { Met }} \times\right.$ sex $)$, with individual $R^{2}$-values of 0.9 and $0.6 \%$, respectively.

\section{Discussion}

The present investigation provides evidence that, indeed, the combined effects of polymorphisms involved in HDL metabolism can explain $12.5 \%$ of the variation of HDL-C plasma levels. Moreover, when sex and several environmental factors were taken into account, a striking $32.5 \%$ of the variation in HDL-C levels could be explained. To our knowledge, this is the largest exploratory study to date to investigate the contribution of genetic variants to plasma HDL-C levels in FH.

It is assumed that the combined effects of multiple common genetic variants might explain a large part of HDL-C variation. ${ }^{13}$ Accordingly, we found that the effect of individual polymorphism genotypes on HDL-C concentration was not impressive. In particular, the $\mathrm{CETP}_{\text {TaqIB }}$ polymorphism showed the strongest association with HDL-C plasma level, but only accounted for $1.1 \%$ of this variation. Indirect evidence has been provided by twin and family studies reporting that genetic background explains $50-70 \%$ of the variation in HDL-C concentration. ${ }^{13,22-24}$ This heritability may be caused by a combination of common genetic variants with a small effect (as shown in our study) and rare genetic variants with a strong effect, as shown recently by Cohen et al. ${ }^{25}$

Several other studies have used a multigenetic approach to explain the variability of plasma HDL-C levels. Previous studies with $\mathrm{FH}$ patients that used a similar approach exhibit important differences with ours. ${ }^{26,27}$ The first study by Miltiadous et al was performed in a small $(n=84)$ cohort of $\mathrm{FH}$ patients, where the individual effects of only five polymorphisms were studied $\left(C_{\text {CTP }}\right.$ Taq1B $_{1}, A p o A I V_{\text {Thr347Ser }}$, ApoAIV $V_{\text {Gly36oHis, }}$ ACE ins/del, and ApoE), and, importantly, interactions between genotypes were not taken into account. The second study by Bertolini et al was performed in a larger cohort of $\mathrm{FH}$ patients $(n=221$ index cases and 
$n=349$ relatives with $\mathrm{FH}$ ), but, again, only eight polymorphisms that could potentially affect $\mathrm{HDL}$ variation were studied (ApoE, LPL ${ }_{A s n 291 S e r} L P L_{\text {Ser447Stopy }} H L_{C(-514) T}$, $H L_{G(-250) A}, F A B P-2_{A 54 T}$ Apo $A V_{T 1131 C}$, and $\left.A B C A 1_{\text {Arg219Lys }}\right)$ and interactions between genotypes were not considered. Other comparable studies performed in the general population, such as a subanalysis of the Northwick Park Heart Study with 2773 healthy middle-aged men and a study performed in the Stanislas cohort, demonstrated that polymorphisms explained only 2.5 and $11.3 \%$ (in men; $16.4 \%$ in women) of the variation of HDL-C plasma levels, respectively. ${ }^{28,29}$ In summary, none of the multigenetic studies performed thus far have examined such a large number of polymorphisms in such a large cohort of FH patients, nor have they demonstrated a similarly large percentage of the variation in plasma HDL-C levels.

Several aspects must be taken into account when interpreting the results of the present study. To begin with, the present study focuses on variation in HDL-C levels and the contribution thereof to the clinical expression in $\mathrm{FH}$. Although the inverse relationship between HDL-C levels and CVD risk is well founded, alterations in HDL-regulating genes that result in high HDL-C levels have not consistently been associated with cardiovascular protection. Several genetic variants have been reported to be associated with a lower risk of CVD, but independent of HDL-C levels. ${ }^{30,31}$ Therefore, studying the contribution of polymorphisms to HDL-C variation should ultimately be translated into their contribution to CVD risk. Moreover, it has been suggested that not only the level of HDL-C but also the composition contributes to CVD risk. ${ }^{32}$ Unfortunately, HDL-C subclasses were not determined in these patients. Future studies in this cohort will be aimed at the association of polymorphisms with CVD risk, as prospectively assessed over time. Secondly, two of the 23 polymorphisms studied were not in HWE. The exact reason for the deviation is not known and we can only speculate on this. Importantly, the deviation from HWE is not due to mixed ethnic groups, as the Dutch population is known to be a homogenous one. Over 99\% of our patients were Caucasian and patients were randomly selected from all over the country. In addition, most deviations were caused by an excess of heterozygotes, which makes genotyping errors unlikely. Furthermore, the accuracy of genotyping in 500 randomly selected DNA samples was assessed by re-analysis of several polymorphisms in three genes, revealing that less than $0.5 \%$ of the results were discordant. Thirdly, due to the retrospective design and reliance on documentation in the medical records, no standardized information was available regarding dietary habits and physical activity. Therefore, we cannot estimate the contribution of these environmental factors that are known to modulate HDL-C plasma levels. Finally, statistical aspects of our study may require some explanation. Statistical analysis of genetic population studies is still in development. A major issue in this field is the interpretation of data sets with a large number of genetic variables. These analyses have a tendency to be 'overfitted', that is, the number of explaining variables approaches or even surpasses the number of observations. In the current analysis, we used 'conventional' multiple linear regression. We incorporated the main effects of genotypes and, subsequently, we selected only those interaction terms that contributed significantly to the explained HDL-C variation after adjustment for all other variables in the model. Our data set comprised 1002 individuals, and the total number of variables in the combined-effects model (with adjustment for covariates) was 72, resulting in a predictor variable to patient ratio of $1: 14$. This ratio is lower than the $1: 10$ ratio that is used as a rough rule of thumb to prevent overfitting. This ratio is based on Harrell et al, ${ }^{33}$ who showed that, for a regression model to have predictive discrimination, the number of predictor variables in a linear regression model should not exceed the number of patients divided by 10 .

Modulation of the expression of the investigated genes to increase HDL-C levels is anticipated to decrease the risk for CVD. This is supported by evidence that a $1 \%$ increase in HDL-C with the use of gemfibrozil can yield a 3\% risk reduction of $\mathrm{CVD}^{34}$ Our results indicate, however, that gene-gene and gene-environment interactions account for a substantial proportion of the overall $32.5 \%$ variation in HDL-C found in this study. Therefore, targeting specific genes may only be efficacious in the context of a specific metabolic background. Nevertheless, pharmacological inhibition of CETP is currently being tested in FH patients to assess their ability to raise HDL-C levels and to induce regression of carotid intima-media thickness. Shortly, ApoA1 mimetics and ABCA1 agonists will follow and will hopefully supplement our armamentarium in the fight against CVD in this high-risk disorder.

\section{Conclusion}

In $\mathrm{FH}$ patients, the variation in HDL-C levels is thought to contribute significantly to the overall risk for CVD in these individuals. However, little is known about the actual contribution of genes and environment to HDL in FH. The present study demonstrates that, in combination with sex and environmental factors, the combined effects of polymorphisms involved in HDL metabolism can explain up to $32.5 \%$ of the variation of HDL-C plasma levels. A better understanding of HDL metabolism may lead to improved cardiovascular risk assessment of FH patients. Furthermore, this may lead the way to the identification of future targets for intervention to improve CVD outcome in these highrisk patients. 


\section{Acknowledgements}

We are grateful for the support of the Netherlands Heart Foundation (grant number 98/165). John JP Kastelein is an established investigator of the Netherlands Heart Foundation (grant D039/ 66510). We are indebted to Roche Molecular Systems personnel of Alameda, California, USA, who supported this study. We thank all patients who participated in the study and the specialists of the participating lipid clinics throughout the Netherlands.

Conflict of interest: None declared.

\section{References}

1 Goldstein JL, Hobbs HH, Brown MS: Familial hypercholesterolemia; in Scriver CR, Beaudet AL, Sly WS, Valle D (eds): The Metabolic Basis of Inherited Disease. New York: McGraw-Hill, 2001, pp 2863-2913.

2 Scientific Steering Committee on behalf of the Simon Broome Register Group: risk of fatal coronary heart disease in familial hypercholesterolaemia. BMJ 1991; 303: 893-896.

3 Sijbrands EJ, Westendorp RG, Defesche JC, de Meier PH, Smelt $\mathrm{AH}$, Kastelein JJ: Mortality over two centuries in large pedigree with familial hypercholesterolaemia: family tree mortality study. BMJ 2001; 322: 1019-1023.

4 Hill JS, Hayden MR, Frohlich J, Pritchard PH: Genetic and environmental factors affecting the incidence of coronary artery disease in heterozygous familial hypercholesterolemia. Arterioscler Thromb 1991; 11: 290-297.

5 Tato F, Keller C, Schuster H, Spengel F, Wolfram G, Zollner N: Relation of lipoprotein(a) to coronary heart disease and duplex sonographic findings of the carotid arteries in heterozygous familial hypercholesterolemia. Atherosclerosis 1993; 101: 69-77.

6 Ferrieres J, Lambert J, Lussier-Cacan S, Davignon J: Coronary artery disease in heterozygous familial hypercholesterolemia patients with the same LDL receptor gene mutation. Circulation 1995; 92: 290-295.

7 Real JT, Chaves FJ, Martinez-Uso I, Garcia-Garcia AB, Ascaso JF, Carmena R: Importance of HDL cholesterol levels and the total/ HDL cholesterol ratio as a risk factor for coronary heart disease in molecularly defined heterozygous familial hypercholesterolaemia. Eur Heart J 2001; 22: 465-471.

8 Jansen ACM, Van Aalst-Cohen ES, Tanck MW et al: The contribution of classical risk factors to cardiovascular disease in familial hypercholesterolemia: data in 2400 patients. J Int Med 2004; 256: 482-490.

9 de Grooth GJ, Kuivenhoven JA, Stalenhoef AF et al: Efficacy and safety of a novel cholesteryl ester transfer protein inhibitor, JTT705, in humans: a randomized phase II dose-response study. Circulation 2002; 105: 2159-2165.

10 Rader DJ: High-density lipoproteins and atherosclerosis. Am J Cardiol 2002; 90 (Suppl): 62i-70i.

11 Ellison RC, Zhang Y, Qureshi MM, Knox S, Arnett DK, Province MA: Lifestyle determinants of high-density lipoprotein cholesterol: the National Heart, Lung, and Blood Institute Family Heart Study. Am Heart J 2004; 147: 529-535.

12 Ordovas JM: HDL genetics: candidate genes, genome wide scans and gene-environment interactions. Cardiovasc Drugs Ther 2002; 16: $273-281$.

13 Heller DH, Faire De U, Pedersen NL, Dahlen G, McClearn GE: Genetic and environmental influences on serum lipid levels in twins. N Engl J Med 1993; 328: 1150-1156.

14 Umans-Eckenhausen MA, Defesche JC, Sijbrands EJ, Scheerder RL, Kastelein JJ: Review of first 5 years of screening for familial hypercholesterolaemia in the Netherlands. Lancet 2001; 357: 165-168.

15 US MedPed Program, www.medped.org, 2005.

16 Scientific Steering Committee on behalf of the Simon Broome Register Group: mortality in treated heterozygous familial hypercholesterolemia: implications for clinical management. Atherosclerosis 1999; 142: 105-112.

17 Defesche J: Familial Hypercholesterolemia; in Betteridge DJ (ed): Lipids and Vascular Disease. London, UK: Martin Dunitz Ltd, 2000, pp 65-76.

18 Jansen ACM, van Aalst-Cohen ES, Hutten BA, Buller HR, Kastelein JJP, Prins MH: Guidelines were developed for data collection from medical records for use in retrospective analyses. J Clin Epidemiol 2005; 58: 269-274.

19 Friedewald WT, Levy RI, Fredrickson DS: Estimation of the concentration of low-density lipoprotein cholesterol in plasma, without use of the preparative ultracentrifuge. Clin Chem 1972; 18: $499-502$.

20 Fouchier SW, Defesche JC, Umans-Eckenhausen MW, Kastelein JP: The molecular basis of familial hypercholesterolemia in The Netherlands. Hum Genet 2001; 109: 602-615.

21 Cheng S, Grow MA, Pallaud C et al: A multilocus genotyping assay for candidate markers of cardiovascular disease risk. Genome Res 1999; 9: 936-949.

22 Hunt SC, Hasstedt SJ, Kuida H, Stults BM, Hopkins PN, Williams RR: Genetic heritability and common environmental components of resting and stressed blood pressures, lipids, and body mass index in Utah pedigrees and twins. Am J Epidemiol 1989; 129: $625-638$.

23 Austin MA, King MC, Bawol RD, Hulley SB, Friedman GD: Risk factors for coronary heart disease in adult female twins. Genetic heritability and shared environmental influences. Am J Epidemiol 1987; 125: 308-318.

24 O'Connell DL, Heller RF, Roberts DC et al: Twin study of genetic and environmental effects on lipid levels. Genet Epidemiol 1988; 5: $323-341$.

25 Cohen JC, Kiss RS, Pertsemlidis A, Marcel YL, McPherson R, Hobbs HH: Multiple rare alleles contribute to low plasma levels of HDL cholesterol. Science 2004; 305: 869-872.

26 Miltiadous G, Cariolou MA, Elisaf M: HDL cholesterol levels in patients with molecularly defined familial hypercholesterolemia. Ann Clin Lab Sci 2002; 32: 50-54.

27 Bertolini S, Pisciotta L, Di Scala L et al: Genetic polymorphisms affecting the phenotypic expression of familial hypercholesterolemia. Atherosclerosis 2004; 174: 57-65.

28 Talmud PJ, Hawe E, Robertson K, Miller GJ, Miller NE, Humphries SE: Genetic and environmental determinants of plasma high density lipoprotein cholesterol and apolipoprotein AI concentrations in healthy middle-aged men. Ann Hum Genet 2002; 66: 111- 124 .

29 Pallaud C, Gueguen R, Sass C et al: Genetic influences on lipid metabolism trait variability within the Stanislas Cohort. J Lipid Res 2001; 42: 1879-1890.

30 Franceschini G, Sirtori CR, Bosisio E et al: Relationship of the phenotypic expression of the A-I Milano apoprotein with plasma lipid and lipoprotein patterns. Atherosclerosis 1985; 58: $159-174$.

31 Zwarts KY, Clee SM, Zwinderman AH et al: ABCA1 regulatory variants influence coronary artery disease independent of effects on plasma lipid levels. Clin Genet 2002; 61: $115-125$.

32 Cheung MC, Brown BG, Wolf AC, Albers JJ: Altered particle size distribution of apolipoprotein A-I cholesterol containing lipoproteins in subjects with coronary artery disease. J Lipid Res 1991; 32: 383-394.

33 Harrell Jr FE, Lee KL: Regression modelling strategies for improved prognostic prediction. Stat Med 1984; 3: 143-152.

34 Rubins HB, Robins SJ, Collins D et al: Gemfibrozil for the secondary prevention of coronary heart disease in men with low levels of high-density lipoprotein cholesterol. Veterans Affairs High-Density Lipoprotein Cholesterol Intervention Trial Study Group. N Engl J Med 1999; 341: 410-418. 